\title{
Die Nachwirkung von Schopenhauers Philosophie in der Musik des 19. und 20. Jahrhunderts [1]
}

\author{
von Ulrike Kienzle
}

Die Auswirkung der Schopenhauerschen Philosophie auf die Musik ist ebenso evident wie schwer beschreibbar. Evident, weil in der Geschichte der Philosophie wohl kein weiterer Fall bekannt ist, in dem sich ganze Generationen von Musikern auf ein und dieselbe Weltanschauung eingeschworen haben und dies in ihren Briefen und Schriften mit bemerkenswertem Eifer bekunden, - schwer beschreibbar, weil Musik eine Sprache ohne Worte ist und weil 'tönende Philosophie' als eine contradictio in adjecto erscheint, die rational kaum zu erklären ist.

Wenn wir nicht im Biographisch-Anekdotischen steckenbleiben wollen, so sind wir einerseits auf die Untersuchung von Vokalmusik angewiesen, in der sich die Semantik eines Textes auf die Faktur der Musik unmittelbar zurückbeziehen läßt; andererseits können wir schriftliche Zeugnisse der Tonkünstler befragen, in denen sie darlegen, inwiefern ihre Kompositionen von Gedanken Schopenhauers inspiriert sind.

Richard Wagner kommt dabei zweifellos eine Schlüsselstellung zu: Er war der erste Musiker, der Schopenhauers Philosophie 'entdeckt' und aus ihr eine neuartige Ästhetik des musikalischen Dramas entwickelt hat. Tristan und Isolde, Die Meistersinger von Nürnberg und Parsifal sind aus dem Geiste der Schopenhauerschen Weltanschauung heraus konzipiert. [2] Damit hat er Schopenhauer der nachfolgenden Komponistengeneration erschlossen: Sie erbte mit den Errungenschaften des 
Musikdramas zugleich auch die philosophischen Überzeugungen ihres Urhebers.

$$
-4-
$$

Wagner steht daher im Zentrum der nachfolgenden Überlegungen; der zweite (kürzere) Teil der Ausführungen wird sich dann mit Hans Pfitzner und Gustav Mahler befassen. Ich beschränke mich - mit Ausnahme Gustav Mahlers - auf Beispiele aus musikdramati-

schen Werken und dabei wiederum auf einige zentrale Aspekte der SchopenhauerRezeption.

Wagners Begegnung mit Schopenhauers Hauptwerk im Jahre 1854 war gleichsam ein Erweckungserlebnis. Der enttäuschte Revolutionär, der sich im Zürcher Exil um seine politischen und künstlerischen Hoffnungen betrogen sah, bezeichnet Die Welt als Wille und Vorstellung als ein - so wörtlich - "Himmelsgeschenk", das "in [s]eine Einsamkeit gekommen" sei. [3] Schopenhauers Bescheid, der Mensch sei Produkt eines sich selbst zerfleischenden 'Willens zum Dasein', er sei von Natur aus ein 'Raubthier', und der Lauf der Geschichte mit all ihren Kriegen und Revolutionen zeige nur das Einerlei eines immer erneuten Leidens, tröstet ihn zunächst über die gescheiterte Revolution hinweg.

$$
-6-
$$

Doch es bleibt nicht bei dieser palliativen Wirkung. Wagner empfindet den Schopenhauerschen Pessimismus als eine vollständige geistige Neuorientierung, die 
eine Fülle eigener Gedanken freisetzt. Wagner macht sich Schopenhauers Ansichten von der Kunst und vom Genie zu eigen, er vertieft sich in erkenntnistheoretische Probleme, befaßt sich mit der Idealität von Zeit und Raum, er konzipiert eine neue Ethik des Mitleidens und des Gewaltverzichts, er studiert indische Literatur, setzt sich mit der Seelenwanderung auseinander und findet zu einem neuen Verständnis des Christentums. In rascher Folge schreibt er mehrere musikästhetische Abhandlungen, in denen er Schopenhauers Musikästhetik konsequent weiterdenkt und frühere Gedanken zum musikalischen Drama unter dem Einfluß der neuen Erkenntnisse revidiert.

\section{$-7-$}

Die weit fortgeschrittene Arbeit am Ring des Nibelungen - dem revolutionären Kunstwerk, in dem Kapitalismuskritik und soziale Utopie ihren Niederschlag gefunden haben - bricht er ab und konzipiert, noch unter dem ersten Eindruck der SchopenhauerLektüre, Tristan und Isolde.

\section{$-8-$}

Ein Liebesdrama als Antwort auf die Schopenhauersche Philosophie? Ist das eine adäquate Reaktion? So ließe sich fragen, denn bekanntlich hat der Philosoph mit aller romantischen Liebesverklärung ein für alle Mal aufgeräumt. Die Liebe ist für ihn ein blinder

Wahn, ein vernunftloser Naturinstinkt. Die Liebenden sind, wie es in der Metaphysik der Geschlechtsliebe nüchtern heißt, die "Verräther [...], welche heimlich danach trachten, die ganze Noth und Plackerei" des Lebens "zu perpetuiren" [4], indem sie den schrecklichen Willen zum Dasein auf die nächste Generation vererben.

Wagner hat diesen Widerspruch sehr wohl bemerkt, und wir werden sehen, wie er sich 
in Parsifal, der bald nach dem Tristan entworfen, aber erst zwei Jahrzehnte später komponiert wird, diesem Problem erneut und aus gewandelter Perspektive stellen wird. Tristan und Isolde entsteht jedoch in einer besonderen biographischen Situation - die Liebe zu Mathilde Wesendonck bleibt unerfüllt, und Wagner bleibt nichts anderes übrig, als seine Erfahrung von der "Liebe als furchtbarer Qual" [5] musikalisch auszugestalten. Dabei ist er, wie sich zeigen wird, nicht so weit von Schopenhauer entfernt.

$$
-10-
$$

Schopenhauers Philosophie ist, was Eros und Sexus betrifft, doppelbödig. Thomas Mann hat dies sehr hellsichtig erfaßt. Er nennt sie rundheraus "eine welt-erotische Konzeption". Sein System ist, so wörtlich, "eine Willensphilosophie von erotischem Grundcharakter, und eben sofern sie das ist, ist der 'Tristan' erfüllt, durchtränkt von ihr." [6] Es scheint, als habe Wagner tatsächlich zuerst jenen "erotischen Grundcharakter" wahrgenommen, der dadurch entsteht, daß nach Schopenhauer alles was lebt - Menschen, Tiere, Pflanzen, selbst die unbelebte Materie - Emanation jenes einen Willens zum Dasein ist, der in allem identisch wirkt und der sich in der sexuellen Anziehung am unmittelbarsten ausprägt.

\section{$-11-$}

Allerdings gibt Wagner diesem Gedanken eine andere Wendung. Ist der Eros "Brennpunkt des Willens", wie Schopenhauer schreibt, so kann die intensive Erfahrung der Liebe $\mathrm{zu}$ einem radikalen Umschlagen der Erkenntnis führen: Indem das Individuum das eigene Begehren als identisch erkennt mit dem Lebenswillen der gesamten Natur, geht es ein in den universalen Weltwillen. So steht es bei Schopenhauer zwar nicht geschrieben, aber Wagner entwickelt diesen Gedanken aus den Prämissen seiner Philosophie, und er verwandelt sie in eine tönende Botschaft. 
Wenden wir uns zunächst der Musik zu. Schon die ersten drei Takte der Einleitung zu Tristan und Isolde enthalten die Keimzelle des ganzen Werkes und gleichsam seine philosophische Grundaussage:

Notenbeispiel 1: Richard Wagner, Tristan und Isolde, Vorspiel I, T. 1-3:

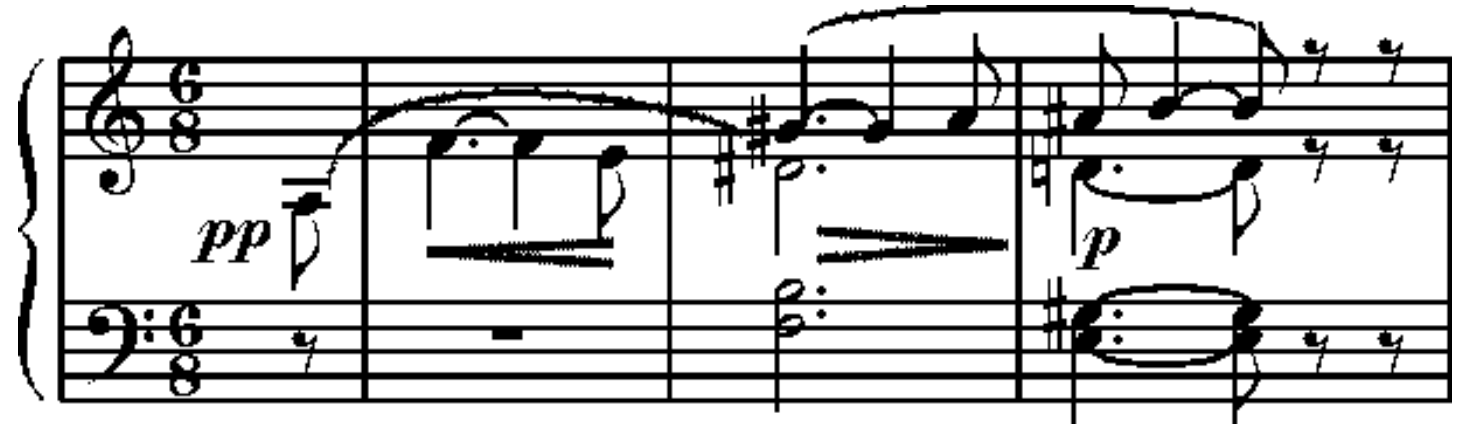

Aus der Stille heraus, dem schweigenden Urgrund der Musik, erhebt sich zunächst ein emphatischer Sext-Aufschwung in den Violoncelli, der lange auf dem Ton $f$ verharrt und sodann wieder in sich zurücksinkt. Dieser Sext-Aufschwung ist ein expressives Ausdrucksmittel, das bereits in der Figurenlehre des Barock als 'exclamatio' ein Zeichen für Klage, Schmerz, Sehnsucht ist. Durch die Instrumentierung mit einer einzigen Instrumentalfarbe - dem Cello - und in einer Lage, die der menschlichen Tenorstimme entspricht, wird dieser Sext-Aufschwung zum Ausdruck einer musikalischen Klangrede mit klagendem Charakter.

Diese Klangrede mündet im zweiten Takt in einen von Holzbläsern intonierten, schmerzlich dissonierenden Akkord - den berühmten Tristan-Akkord, der sich harmonisch nur schwer deuten läßt. Er ist gleichsam eine musikalische Urzeugung, und als solche ist er im Werk omnipräsent. Wagner hat diesen Akkord offensichtlich als Klangsymbol für den in sich zerrissenen, gespaltenen Weltwillen aufgefaßt. 
Im zweiten Takt löst sich aus diesem Akkord ein chromatischer Gang aufwärts vom gis zum $h$ in den Oboen. Wagner hat auch dieser musikalischen Figur Symbolcharakter beigemessen. In einem Brief an Mathilde Wesendonck vom 3. März 1860 bezieht er dieses Motiv auf die "buddhistische Weltentstehungstheorie", von der er in Schopenhauers Parerga gelesen hat [7]:

Notenbeispiel 2: Richard Wagner, Tristan und Isolde, Vorspiel I, T. 2f:

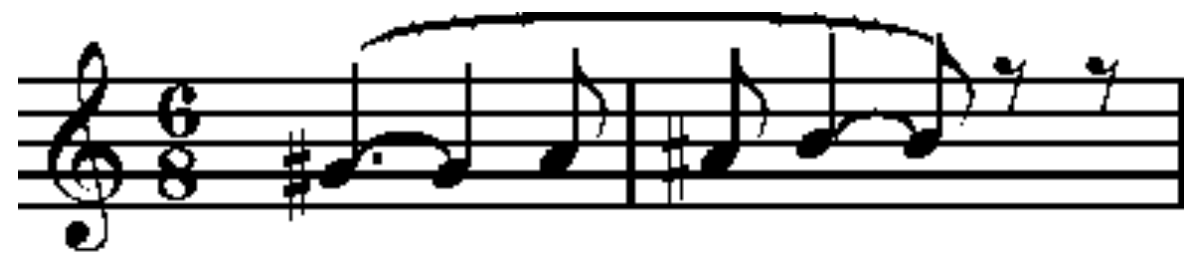

"Ein Hauch trübt die Himmelsklarheit", schreibt er, und zeichnet in dem Brief jenen chromatischen Gang auf.

$$
-15-
$$

Er fährt fort: "das schwillt an, verdichtet sich, und in undurchdringlicher Massenhaftigkeit steht endlich die ganze Welt wieder vor mir." [8] Der Anfang des Tristan-Vorspiels, so dürfen wir aus dieser Briefstelle folgern, beinhaltet einen 
Weltentstehungsmythos, die Quintessenz der Welt im Sinne Schopenhauers. Der Grundcharakter jener drei Takte ist der einer Sehnsucht, die nicht erfüllt wird, und einer schmerzlichen Spannung, die sich nicht lösen kann.

$$
-16-
$$

Aus der sequenzierenden Ausgestaltung und variativen Fortspinnung dieses Urmodells gewinnt Wagner im weiteren Verlauf des Vorspiels eine Intensivierung dieser Spannung. Sie löst sich sodann in einer weiträumig entfalteten melodischen Bewegung in den Celli:

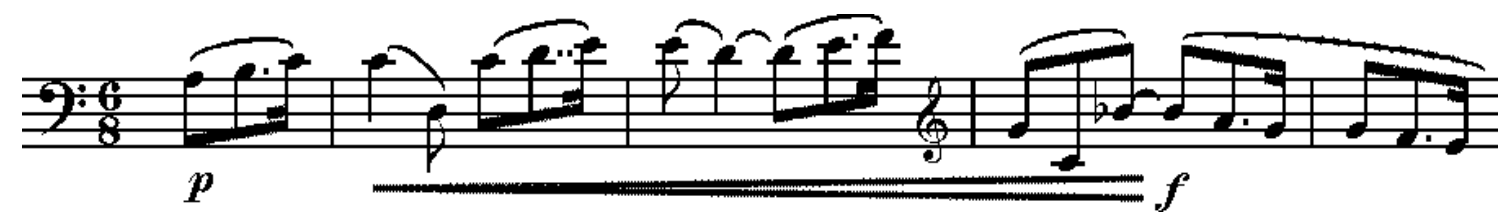

die aber sofort ihrerseits Ausgangspunkt einer schier endlosen Folge von Variationen und Sequenzen wird, in denen sich die anfängliche Sehnsucht permanent fortzeugt und sukzessiv steigert, bis sie wieder in sich zurücksinkt. Am Ende steht die Rückkehr zum Anfang: Die beredte Klage der Sexte beginnt aufs neue, wieder erklingt der TristanAkkord, gefolgt von dem chromatischen Anstieg.

$$
-17-
$$

Die Quintessenz der Welt, aus der Sicht des Individuums betrachtet, ist nach Wagners Schopenhauer-Verständnis die Liebe in ihrem Charakter als unerfüllbare Sehnsucht. Dieser Aspekt gibt dem Vorspiel eine doppelte Programmatik: Es ist Ausdruck des Willens zum Dasein und Liebesklage zugleich. 
Dem 'inneren Drama' des Vorspiels folgt sodann das 'äußere Drama'. Der musikalische Reichtum der Tristan-Partitur entfaltet sich aus der Keimzelle des Vorspiels. Im Verlauf des ersten Aktes gewinnen die ersten drei Takte des Vorspiels und die Cello-Kantilene eine spezifische dramaturgische Bedeutung. Der chromatische Aufstieg erklingt zunächst als Zeichen für die ungebändigten Elemente der Natur - für Meer und Sturm. Er steht aber auch für die geheimnisvollen Tränke, in denen Isoldes Mutter die Quintessenzen der Natur, ihre magischen und alchimistischen Kräfte, gebannt hat. Und der chromatische Aufstieg erklingt zusammen mit der emphatischen Sexte, wenn Isolde von sich selbst und von ihrer unerfüllten Liebe zu Tristan spricht. Die chromatische Figur ist somit tönende Chiffre für die Totalität der 'Welt' im Schopenhauerschen Sinne und benennt das Ineins von Innen- und Außenwelt, von Individuum und Universum.

$$
-19-
$$

Die Liebe Tristans und Isoldes entspringt einem exzeptionellen Moment der Entgrenzung von Raum und Zeit, in dem die Bedingungen der Lebenswirklichkeit für einen Augenblick außer Kraft gesetzt sind. Dieser entscheidende Moment wird im Drama selbst nur berichtet, aber die Musik verhilft ihm zur akustischen Präsenz. Im Augenblick der Begegnung des todwunden Ritters mit Isolde, die in ihm den Feind erkannt hat, den sie töten will, begegnen sich beider Blicke: "Er sah mir in die Augen", erinnert sich Isolde, "seines Elends jammerte mich". Dazu erklingt der chromatische Aufstieg aus dem Vorspiel, gefolgt von jener weichen Kantilene, die hier als Motiv der erwachenden Liebe kenntlich wird.

$$
-20-
$$

Isoldes Liebe entspringt der Erfahrung des Leidens. Aber dieses Leiden ist nicht auf Tristan allein beschränkt: Isolde hat durch Tristans Blick den Leidenscharakter des Daseins erfahren, von dem Schopenhauers Philosophie kündet. Das sagt die Musik, indem sie jenen chromatischen Aufstieg wiederholt, der das Total der Schopenhauerschen Welt symbolisiert. Tristans Elend ist zugleich das Elend der Welt als Wille. Die Liebe hat also von Anbeginn nicht nur eine erotische, sondern auch eine metaphysische Dimension. 
Dies ist auch die Bedeutung des Todestranks, den Isolde mit Tristan trinken will, um den Moment der gemeinsamen Welterkenntnis zu konfirmieren. Tristan hat ihn verraten, indem er in die Welt der Erscheinung zurückgekehrt ist und weiterhin im höfischritterlichen Ehrenkodex - um mit Schopenhauer zu sprechen: im 'Schleier der Maja' verhaftet bleibt. Isolde jedoch will jenen transitorischen Moment, der in der Begegnung

der Blicke ihrer beider Liebe begründet hat, durch Eintauchen in den Urzusammenhang des Weltwillens zur Ewigkeit erheben.

Die vorgebliche Verwechslung von Todes- und Liebestrank ist eine dramaturgisch sinnfällige Metapher für die Täuschung, der beide erliegen: Der Selbstmord, so Schopenhauer, bedeutet keineswegs das Ende des Lebens, sondern nur das Ende der Individualität. Das unendliche Begehren zeugt sich über den Tod hinaus unvermindert fort. So sterben auch Tristan und Isolde nur einen symbolischen Tod; in Wirklichkeit verfallen sie dem Eros, dem Brennpunkt des Willens, und sind dem daraus entspringenden Leiden unausweichlich ausgeliefert.

$$
-23-
$$

Wagner verdeutlicht diese Zusammenhänge, indem er im Anschluß an das gemeinsame Trinken des vermeintlichen Todestrankes die Musik aus dem Vorspiel wiederholt, die ja ihrerseits als eine musikalische Umschreibung der Weltentstehung aus dem Willen gedeutet werden kann. Dies ist der Moment einer Initiation. Von jetzt an leben Tristan und Isolde in ihrer eigenen Welt. Alles, was vorher wichtig war, ist nun wesenlos: "Was träumte mir von Tristans Ehre?" - "Was träumte mir von Isoldes Schmach?" 
Wagners Tristan ist Welttheater aus dem Geiste der pessimistisch-idealistischen Philosophie Arthur Schopenhauers. Dementsprechend gestaltet Wagner das große Liebesgespräch des zweiten Aktes als philosophischen Diskurs. Dem ekstatischen Jubel des Wiedersehens folgen metaphysische und dialektische Spekulationen.

$$
-25-
$$

Tristan und Isolde finden dabei zu einer poetischen Sprache, die von einem dichten Netz von Symbolen und Metaphern durchzogen ist. Sie bilden ein System von Antithesen: Sie umkreisen die Assoziationsfelder 'Liebe', 'Nacht', 'Nähe' und 'Wahrheit', die für die neue Erkenntnis der Welt als Wille stehen, und 'Tag', 'Trennung', 'Täuschung', die das Leiden unter dem Schleier der Maja kennzeichnen. Die metaphysische Weltsicht der Liebenden soll auf diese Weise von der gewöhnlichen, in Wahn und Schein befangenen Wahrnehmung der übrigen Welt abgehoben werden.

$$
-26-
$$

Tristan und Isolde verschmelzen quasi zu einer Person - mehr noch: Sie erkennen sich als identisch mit dem Universum. "Selbst dann bin ich die Welt", singen sie zu den Tönen des Tristan-Akkords, der musikalischen Chiffre des Weltwillens. Diese Selbsterkenntnis als Welterkenntnis verdankt sich der idealistischen Anschauung Schopenhauers,

die für Wagner neu war. In der Überwindung des principium individuationis verbindet sich das Subjekt mit dem universalen Willen und verschmilzt mit ihm; dadurch erkennt sich das Ich als Träger der Welt und damit als allmächtig. Im Tristan ist diese Erfahrung als lustvolle Einswerdung von Mensch und Natur gestaltet.

Mit der Verherrlichung der Nacht und des Todes als der nicht mehr scheinhaften 
Existenz und als Erlebnisraum einer Liebe, die unsterblich ist, entfernt sich Wagner jedoch - zumindest dem Anschein nach - von Schopenhauers pessimistischem Blick auf die Metaphysik der Geschlechtsliebe und greift auf romantische Traditionen zurück. So finden sich wörtliche Übereinstimmungen mit Passagen aus den Hymnen an die Nacht von Novalis und mit dem Zwiegespräch der Liebenden aus Friedrich Schlegels Roman Lucinde. Auch der mystische Pantheismus von Ludwig Feuerbachs Gedanken über Tod und Unsterblichkeit, die Wagner bereits in den vierziger Jahren gelesen hat, ist präsent.

$$
-28-
$$

Zugleich werden die ausgeklügelten Reflexionen der Liebenden von der Musik eindrucksvoll kontrapunktiert, indem sie das, was die Liebenden ersehnen, bereits als erfüllte Gegenwart imaginiert. Mit ihren verschwebenden Synkopen und Überbindungen, die das Metrum des Taktes verschleiern, suggeriert sie ein Stillstehen der Zeit und damit das Eingehen der Liebenden in die ewige Gegenwart der Liebesnacht. Der fluktuierende Klangteppich der Streicher entfaltet aus einfachen Tonrepetitionen, die sich allmählich über die Terz bis zum Dreiklang erweitern, eine flutende Klangfläche. Die prismatische Aufspaltung des Klangraums entspricht der Weitung des Bewußtseins in der Überwindung von Zeit und Raum.

Die Melodie von Tristans Worten: "O sink hernieder, Nacht der Liebe", besteht aus dem horizontal entfalteten Tristan-Akkord. Die Spannung der vertikalen Zusammenballung aus dem Vorspiel, das als Sinnbild der Zerrissenheit des Weltwillens zu deuten ist, wird hier in lyrisches Melos aufgelöst. Dadurch erscheint das Leiden an der Liebe virtuell aufgehoben.

$$
-30-
$$

Es scheint, als sei Wagner hier seinem philosophischen Mentor untreu geworden. Aber lassen wir uns nicht täuschen: Die Verherrlichung der Liebe, die so zwingend aus dieser Musik spricht, erscheint bereits hier in zwiespältiger Beleuchtung. Wagner erhält eine eigentümliche Brechung aufrecht: Die musikalisch beschworene Liebesnacht wird sprachlich im Konjunktiv, als Frage oder Bitte, als Wunsch formuliert. Während die Lie- 
benden sich in die Vision der ewigen Liebesnacht bis zur Ekstase hineinsteigern, spiegelt der Text den Bruch zwischen Realität und Traum.

Im dritten Akt wird dieser Widerspruch offenbar. Er steht im Zeichen der totalen Desillusionierung, der existentiellen Trostlosigkeit. Die Liebe zu Isolde - im zweiten Akt noch als erlösend verstanden - ist jetzt Ursache von Tristans Leiden. Sie wirft ihn der 'Täuschung' des Tages, dem 'Trug und Wahn' wieder zu, den er überwunden glaubte. Tristan begreift sein Schicksal als ewiges Sehnen, das nicht sterben kann - ganz so wie Schopenhauer in der Metaphysik der Geschlechtsliebe die endlose Perpetuierung des Leidens durch die Liebe erkannt hat.

Tatsächlich ist Wagner der Schopenhauerschen Konzeption der Liebe also sehr nahe. Daher ist es durchaus konsequent, wenn Tristan auf dem Höhepunkt seiner Verzweiflung sich selbst als Urheber des verfluchten Trankes begreift: Der Liebestrank ist Quintessenz des Willens zum Dasein, und das leidende Individuum trägt den Willen in seiner Gesamtheit in sich. In Tristan, der nicht sterben kann, der sich "ew'ger Qual vererben" muß, meditiert der leidende Weltwille über seine eigene Zerrissenheit.

Die Destruktion der Liebesbegeisterung greift über auf die musikalische Faktur. Formale, harmonische und melodische Ordnungen werden zunehmend aufgesprengt. Leitmotive sind nur noch als Torsi, als abgespaltene Fragmente oder in geisterhafter Verzerrung kenntlich - so auch die emphatische Sexte und das chromatische Sehnsuchtsmotiv aus dem Vorspiel. Wagner war sich bewußt, daß er mit dieser Musik an die Grenzen dessen ging, was er seinen Zuhörern zumuten konnte. 
Und der junge Friedrich Nietzsche, der den Tristan gerade wegen seiner konsequenten Schopenhauer-Adaption als 'opus metaphysicum' geschätzt hat, stellt die Frage, ob es einen musikalisch sensiblen Menschen gebe, "der den dritten Akt von Tristan und Isolde ohne alle Beihilfe von Wort und Bild, rein als ungeheuren symphonischen Satz zu perzipieren imstande wäre, ohne unter einem krampfartigen Ausspannen aller Seelenflügel zu veratmen? Ein Mensch, der wie hier das Ohr gleichsam an die Herzkammer des Weltwillens gelegt hat, [...] er sollte nicht jählings zerbrechen?" [9]

Die symphonische Struktur dieser Musik, so Nietzsche, vermittelt die Schrecklichkeit des Daseins mit unverminderter Schonungslosigkeit; der Mythos aber (die dramatische Handlung) schützt wiederum vor den Konsequenzen dieser Erkenntnis, indem er die Aufmerksamkeit des Rezipienten auf den tragischen Helden richtet, in dessen Leid und Untergang von der universalen Bedeutung dieses Leidens abgelenkt wird: Das Mitleiden mit dem Helden rettet vor dem Urleiden der Welt.

$-36-$

Vor dem Hintergrund dieser Überlegungen ist auch die musikalische Utopie des TristanSchlusses zu verstehen. Das Erlebnis der Entgrenzung, das Isolde zuteil wird, die Ekstase des Eingehens in den Weltwillen, ist zweifellos ein musikalisches Äquivalent der Vision des 'Nirwana', des seligen Nichts, mit der das vierte Buch der Welt als Wille und Vorstellung schließt. Auch Schopenhauers Hauptwerk endet schließlich nicht in Verzweiflung, sondern mit einer, wenn auch negativen, Utopie. 
In Tristan und Isolde kommt der Musik eine für Wagner neuartige Funktion zu: Sie entläßt das Drama gleichsam aus sich, indem Handlung und Text - weit mehr als in den vorangehenden Werken - als bloße Explikation dessen erscheinen, was die Musik in der ihr eigenen Sprache zum Ausdruck bringt. Wagner traut der Musik eine semantische Ausdrucksdichte $\mathrm{zu}$, die den Text überlagert, ihn mit sich fortträgt oder ihm eine Bedeutung verleiht, die der sprachlichen Aussage allein nicht zukommt.

Umgekehrt ist der Text des Tristan von einer tiefgreifenden Sprachskepsis geprägt: Wenn die Protagonisten miteinander reden, dann tun sie das entweder in einer formelhaft erstarrten Sprache, wie im ersten Akt, oder in der ebenfalls artifiziellen Form der philosophischen Spekulation wie im zweiten. Schweigen und Verschweigen, NichtSagen-Können und Nicht-Sagen-Wollen sind zentrale Aspekte einer Sprach-Not, die dem tiefen Blick in die Welt als Wille erwächst.

$$
\text { - } 39 \text { - }
$$

Die Sprache, so Schopenhauer, ist, wie Vernunft und Verstand, ein Werkzeug des Individuums im Kampf der Objektivationen des Willens untereinander. Aus diesem Befund entwickelt Wagner eine fundamentale Sprachkritik. Wie kann Sprache zur Mitteilung

metaphysischer Erkenntnis taugen, wenn sie in Zeit und Raum, den Formen der Erkenntnis und damit in der Welt der Erscheinung verhaftet ist? Sprache kann lediglich ein Katalysator sein und durch logische Beweisketten einen intuitiven Erkenntnisprozeß beschleunigen. 
Als eigentliche Vermittlerin philosophischer Wahrheit aber begreift Wagner die Musik. Sie nimmt auch bei Schopenhauer eine Sonderstellung unter den Künsten ein, da sie nicht, wie die übrigen, ein Abbild der Ideen liefert, sondern eine ebenso unmittelbare Objektivation des Willens ist wie die Welt selbst. Musik, sagt Schopenhauer, spricht "das innere Wesen, das Ansich der Welt" in einer "höchst allgemeinen Sprache" aus, "nämlich in bloßen Tönen", aber sie tut das "mit der größten Bestimmtheit und Wahrheit". Der Komponist "offenbart das innerste Wesen der Welt und spricht die tiefste Weisheit aus, in einer Sprache, die seine Vernunft nicht versteht; wie eine magnetische Somnambule Aufschlüsse giebt über Dinge, von denen sie wachend keinen Begriff hat." [10]

Schopenhauer stellt die Musik damit gleichberechtigt an die Seite der Philosophie: Wenn es gelänge, schreibt er, "eine vollkommen richtige, vollständige und in das Einzelne gehende Erklärung der Musik, also eine ausführliche Wiederholung dessen was sie ausdrückt in Begriffen zu geben", so würde dies "die wahre Philosophie seyn". Eben deshalb, heißt es an anderer Stelle, "ist die Wirkung der Musik so sehr viel mächtiger und eindringlicher, als die der andern Künste: denn diese reden nur vom Schatten, sie aber vom Wesen." [11]

Aus solchen Prämissen entwickelt Wagner in seiner Beethoven-Festschrift von 1870 eine neue Konzeption des musikalischen Dramas. Er korrigiert damit die Thesen seiner früheren Zürcher Kunstschriften, in denen er dargelegt hatte, daß Sprache und Musik im Dienste des Dramas stehen und lediglich dessen Ausdrucksmittel sind. Die Musik erhält jetzt, nach der Schopenhauer-Lektüre, eine ganz neue, fundamentale Bedeutung: Sie ist nicht mehr Mittel zum Zweck des Dramas, sondern Wagner begreift sie als dessen Urgrund, als Emanation der unmittelbaren Wesensschau. Sie ist Künderin des Unsagbaren, indem sie die Erkenntnis von der Identität alles Lebenden dem Gefühl des Zuhörers mitteilt. 
Allerdings erwächst daraus ein Problem: Da Musik im Unbegrifflichen verbleibt, ist sie für den in Zeit, Raum und Kausalität verhafteten Rezipienten nicht unmittelbar verständlich. Er erfährt sie als dunkles Raunen. Daher, so Wagner, braucht die Musik die Bindung an die Welt der Erscheinungen. Sie muß sich mit der dichterischen Idee verbinden, mit Sprache und Bild. So entsteht das musikalische Drama, dessen mythische Handlung die unbegriffliche Aussage der Musik an die sinnliche Anschauung des Rezipienten vermittelt. Dementsprechend bezeichnet Wagner seine musikalischen Dramen als "ersichtlich gewordene Thaten der Musik." [12]

Da Musik jenseits von Zeit und Raum gleichsam als Urzeugung des Willens entsteht, muß sich der Komponist im Augenblick der schöpferischen Inspiration von den gewöhnlichen Formen der Anschauung lösen. Dies gelingt durch Introspektion. Schon früher hatte Wagner beobachtet, daß beim intensiven Musikhören die Außenwelt versinkt und das in die ästhetische Kontemplation versunkene Subjekt eigenmächtig Bilder erzeugt. Dieser Vorgang gleicht dem Traum. Beides - die ästhetische Kontemplation und der Traum - sind Grenzerfahrungen des psychischen Erlebens, und in beiden hat das Subjekt Zugang zu unbewußten Seelenschichten, die dem Wachbewußtsein verborgen sind.

Im tiefsten Traum, so Wagner, überwindet das Subjekt die Schranken der Individuation und taucht in die Welt als Wille ein. Was es dort wahrnimmt, ist rational nicht erklärbar. Das nach innen gerichtete 'Traumorgan' erzeugt jedoch Bilder, indem es die Innenschau des Unbewußten in die sinnlichen Formen übersetzt und somit eine Brücke von der Welt als Wille zur Welt als Vorstellung schlägt. 
Auf die gleiche Weise entsteht nach Wagners Überzeugung das musikalische Drama, indem der Musiker seine Sinne von der Außenwelt abzieht, das principium individuationis gleichsam überwindet und sich mit dem Ansich der Welt verbindet. Im Zustand der ästhetischen Kontemplation vertraut er sodann auf die eigenschöpferische Kraft des 'Traumorgans'. Im Gegensatz zum Traum ist dies jedoch ein Zustand höchster Bewußtheit. Im Augenblick der künstlerischen Inspiration, so Wagner, wird "der zum Schweigen gebrachte individuelle Wille im Musiker als universeller Wille wach". Er erkennt sich selbst als identisch mit dem Weltganzen. "Diese ungeheure Überflutung aller Schranken der Erscheinung", schreibt Wagner weiter, "muß im begeisterten Musiker notwendig

eine Entzückung hervorrufen, mit welcher keine andere sich vergleichen ließe: in ihr erkennt sich der Wille als allmächtiger Wille überhaupt: nicht stumm hat er sich vor der Anschauung zurückzuhalten, sondern laut verkündet er sich als bewußte Idee der Welt." [13]

In den Meistersingern von Nürnberg thematisiert Wagner diese neuartige Psychologie der künstlerischen Inspiration und verbindet sie mit einer sozialpolitischen Konzeption. Im dritten Akt erklärt Hans Sachs dem jungen Walther von Stolzing, wie ein "Meisterlied" entsteht. Der Ritter hatte einen "wunderschönen Traum", und Hans Sachs rät, das fast schon vergessene Traumbild durch Poesie ins Bewußtsein zurückzuholen 
und daraus zur Erkenntnis der gegenwärtigen Lebenssituation zu gelangen. "Glaubt mir, des Menschen wahrster Wahn / wird ihm im Traume aufgetan", erklärt er, und er fügt hinzu: "All' Dichtkunst und Poeterei / ist nichts als Wahrtraum-Deuterei".

Hier findet sich Wagners Ästhetik von der künstlerischen Inspiration wieder: Der Dichter, der im Traum Zugang zu den Tiefen des Unbewußten und damit zu einem freilich unbegrifflichen Wissen über die wahre Beschaffenheit der Welt hat, die ihm im Wachbewußtsein verlorengeht, muß die erschauten Bilder in poetische Metaphern und in tönende Klänge umwandeln. Die anschließende Deutung dieses unbewußt empfangenen Wissens weist ihm dann den Weg $\mathrm{zu}$ sinnvollem und ethisch verantwortungsvollem Handeln. Insofern ist die Kunst in den Meistersingern ein Medium der Selbsterkenntnis.

Sie hat darüber hinaus noch zwei weitere fundamentale Funktionen. Sie ist - erstens ein Spiegel der Gesellschaft, indem die 'Meisterregeln' in abstrakter Form die Gesetze des Zusammenlebens in der Gemeinschaft in sich enthalten. Diese Gesetze sind wiederum notwendig, um den zerstörerischen Aspekt des Willens, der in den Meistersingern als blinder 'Wahn' erscheint, zu bändigen und dem einzelnen Individuum einen Raum zu freier Selbstentfaltung im Rahmen der Gemeinschaft zu gewähren. Für den jungen Ritter Walther von Stolzing ist das Erlernen der Meisterregeln daher zugleich eine Übung in bürgerlicher Lebensführung.

Für Hans Sachs, in dessen Gestalt Wagner die tragische Erkenntnis der Welt als 'Wille' 
personifiziert hat, bietet die Kunst - zweitens - metaphysischen Trost, der ihn über die Fährnisse der tragischen Weltsicht hinweg vor den Konsequenzen des Pessimismus, vor Lebensüberdruß und Resignation bewahrt - und dies nicht als bloßes Palliativ, sondern indem ihm als Künstler im Augenblick der schöpferischen Inspiration, wie er sagt, "die Welt zu Füßen" liegt.

$$
-51-
$$

Die Utopie eines Gemeinwesens auf der Grundlage der Kunst verbindet Wagners frühe Ideen der Revolutionszeit mit den Prämissen der Schopenhauerschen Philosophie. Und dennoch ist dieses Staatswesen, wie die Schlußansprache von Hans Sachs deutlich macht, zutiefst gefährdet: Es wird untergehen - dies ist unvermeidliche Konsequenz der Zerrissenheit des Weltwillens und spiegelt das universelle Leiden auf der Ebene der Politik. Die Kunst jedoch ist nicht allein das 'Paradies', in welches das leidende Individuum sich vor den Widrigkeiten der Zeitläufte flüchten kann, sondern sie ist zugleich der Lebensquell, aus dem sich die zerrüttete politische Ordnung immer wieder zu regenerieren vermag. Das ist die oftmals mißverstandene Botschaft der Schlußszene von Wagners Meistersinger-Dichtung. [14]

Gegenüber den versöhnlichen Meistersingern erscheint die Schopenhauer-Rezeption in Parsifal bei weitem radikaler. Wagners 'Weltabschiedswerk' bezieht seine Substanz aus dem 'Unzeitgemäßen' der Schopenhauerschen Philosophie, aus ihrer kritischen Sprengkraft, die darin liegt, daß sie die ethischen und sozialen Grundlagen des modernen Lebens - materielles Wohlergehen, die Selbstbereicherung weniger auf Kosten vieler, die Unterwerfung der Natur zugunsten des Menschen und eines fragwürdigen technischen Fortschritts - als nichtig und verwerflich brandmarkt.

Das Bühnenweihfestspiel steht im Zeichen der Verweigerung. Der Gralsorden ist ein Gegenentwurf zur modernen Welt - die Vision eines friedlichen Zusammenlebens von 
Mensch und Natur auf der Grundlage einer Ethik des Mitleidens. Der freiwillige Verzicht

auf die Befriedigung egoistischer Triebenergie wird zum Fundament einer neuen, idealen Gemeinschaft. Mit seinen Maximen der Askese, der Gewaltlosigkeit, des tätigen Handelns zugunsten anderer und der mystischen Versenkung ist der Gralsorden als künstlerischer Reflex des vierten Buches der Welt als Wille und Vorstellung zu verstehen. Das Gralsmysterium ist der Versuch einer Lösung von Zeit und Raum in der religiösen Kontemplation und einer Aufhebung des principium individuationis in der mystischen Gemeinschaft.

Allerdings führt Wagner in aller Eindringlichkeit die Gefährdung dieser Utopie vor. Der universale Konflikt zwischen der Bejahung und Verneinung des Willens wird hier am Beispiel der Sexualität ausgetragen. An jeder der Figuren exemplifiziert Wagner eine andere Spielart des Umgangs mit dem Eros. Die Gralsritter verfallen den erotischen Verlockungen in Klingsors Zaubergarten. Die Blumenmädchen, denen sie dort begegnen, verkörpern den unbewußten Triebwunsch der Natur; es sind pflanzenhafte Geschöpfe. In Kundry kommt der universale Zwiespalt zum Bewußtsein. Im zwanghaften Wechsel ihrer Existenzen zwischen Askese und Verführung trägt sie die Selbstzerrissenheit des Willens in ihrer Person aus. Amfortas, der ihr verfällt, ist ebenfalls gespalten zwischen Liebessehnsucht und der Erkenntnis ihrer Verwerflichkeit. Seine Schuld manifestiert sich in der unheilbaren Wunde, die nicht nur seine Physis, sondern vor allem seine Psyche zerfrißt.

In der Figur Parsifals dagegen hat Wagner seine Vorstellung vom Lebensweg des 'Heiligen' im Sinne Schopenhauers dramatisch gestaltet: Es ist kein geradliniger Weg, 
und vor allem ist es ein Weg der Erfahrung, nicht der abstrakten Spekulation oder des blinden Glaubens. Parsifals Schuld am Tod der Mutter und sein gedankenloser Schwanenmord weisen ihn zunächst als den ahnungslosen 'Toren' aus, dem die Erkenntnis von der Identität alles Lebenden noch nicht aufgegangen ist. Er bleibt bis zur Mitte des Dramas noch ganz im principium individuationis und damit im schuldhaften Dienst am Willen verhaftet. Erst die Erfahrung der erotischen Verführung durch Kundry und damit das Erlebnis des Urgrundes der Welt im Geschlechtstrieb führt zu einem plötzlichen Umschlagen der Erkenntnis.

$$
-56-
$$

Durch Kundrys Verführung taucht Parsifal tief in die 'Welt als Wille' ein. Das Liebeserlebnis gewinnt hier eine ähnliche Bedeutung wie im Tristan - allerdings mit völlig anderen Konsequenzen. Im Augenblick der höchsten Steigerung des erotischen Verlangens begreift Parsifal den Willen zum Dasein als Quelle des Leidens zunächst des Amfortas;

sodann erweitert sich diese Erkenntnis auf alles Lebende. Die Liebessehnsucht konfrontiert Parsifal mit dem Willen in seiner Zerrissenheit. Er durchschaut die Befriedigung der sexuellen Triebenergie als Bestätigung eines unersättlichen Egoismus. Liebe - dies begreift Parsifal plötzlich und intuitiv - darf nicht als Eros auf das Individuum beschränkt bleiben, sondern sie muß sich als Agape auf die ganze Welt erweitern. Durch diese Erkenntnis wird aus dem 'Toren' der 'Erlöser'.

$$
-57-
$$

Durch die Überwindung der Triebkräfte des Willens gewinnt Parsifal metaphysische Freiheit. Er wird gerade dadurch zum 'Heiligen', daß er die Leiden und Konflikte von Amfortas und Kundry selbst durchlebt, ihre Verwundungen und Irrnisse auf sich nimmt und ihre Verfehlungen gleichsam korrigiert. In dieser Tugend des Mitleidens und der 
freiwilligen Übernahme von Leiden tritt Parsifal die Nachfolge von Christus an. Damit vollendet sich auch die Heilstat Christi, die Wagner nicht als einmaliges Sühneopfer, sondern - ganz im Sinne Schopenhauers - als Aufforderung zur Nachahmung versteht.

$$
-58-
$$

Allerdings richtet sich Parsifals freiwilliges Leiden nicht auf das Selbstopfer, sondern auf eine Erlösung zum Leben. Sie zeigt sich zunächst im Aufblühen der Natur am Karfreitagsmorgen und bewährt sich schließlich in der Wiederherstellung der Gralsgemeinschaft als eines Refugiums, in dem die Grausamkeit des Weltwillens exemplarisch aufgehoben erscheint.

Wagners letztes Werk ist ein symbolistisches Mysterienspiel, in dem Wagner entscheidende Aspekte der Schopenhauerschen Philosophie in konzentrierte Bilder gefaßt hat. Diese Bilder und sprachlichen Metaphern sind mehrdeutig; hinter ihnen eröffnen sich immer neue Bedeutungsschichten und gedankliche Horizonte. Der rationale und emotionale Nachvollzug dieser Dramenhandlung erfordert eine spezifische Haltung der ästhetischen Kontemplation, in der sich der Zuhörer zunächst ganz auf die fremdartige und rätselhafte Symbolik einläßt und die sakrale Aura des Werkes gleichsam als einen Gang in die Tiefen des Unbewußten und des Traumes in sich aufnimmt.

$$
-60-
$$

Dabei leitet ihn die Musik. Schon das Vorspiel gleicht einem Initiationsritus: Das diatonisch aufsteigende, getragene Abendmahlthema, das unisono von Holzbläsern und Streichern vorgetragen wird, verleugnet durch seine synkopische Rhythmisierung in sehr langsamem Tempo das vorgezeichnete Metrum und endet in einer Aura aus statisch an- 
mutenden, auf und ab wogenden Triolen in den Bläsern und irisierenden, gebrochenen Zweiunddreißigstel-Akkorden in den Streichern:

Notenbeispiel 4: Richard Wagner, Parsifal, Vorspiel I, T. 1-7 und 15-19:
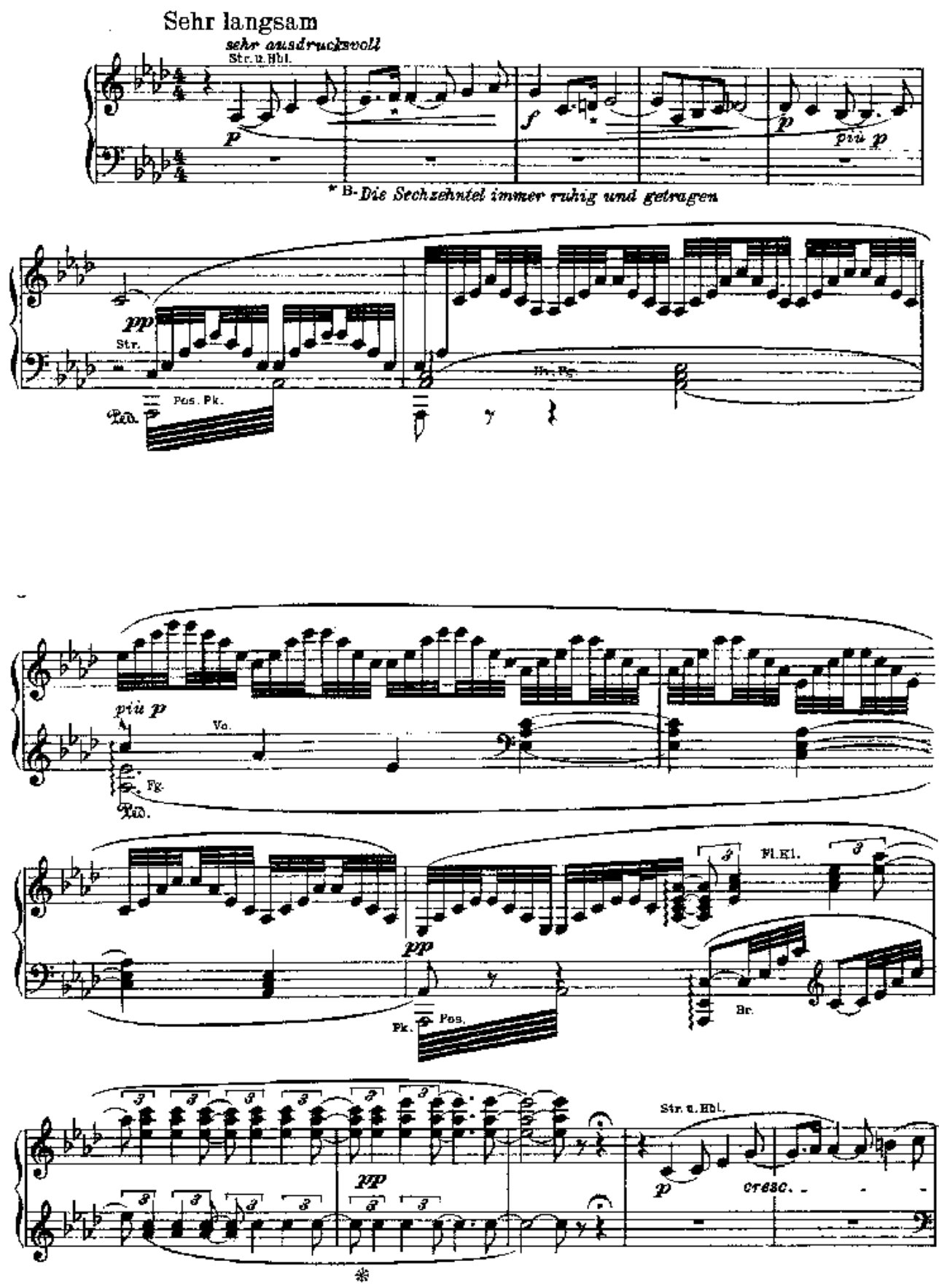
Diese Bewegung öffnet den Klangraum und suggeriert zugleich einen Stillstand. Horizontale und Vertikale fallen ineins.

Durch die dreimalige, harmonisch und instrumental wechselnd ausgeleuchtete Wiederholung dieser Anfangsformel, die immer wieder in die Klangaura einmündet, entsteht der Eindruck einer ganz neuen Zeitqualität: Sie ist nicht linear und zielgerichtet, sondern sie erhebt den Augenblick zu einem 'Nunc stans', zu einer ewigen Gegenwart. Der Zuhörer soll dadurch von der Welt der Erscheinung und ihren Bedingungsformen gelöst werden, so daß er das folgende Drama wie einen hellsichtigen Traum erfährt und in einen quasi meditativen Zustand des Hellsehens versetzt wird.

$$
-62-
$$

Das Ineinanderfallen von Raum und Zeit als Zeichen des Übergehens in die gewandelte Wahrnehmung der ästhetischen Kontemplation wird später auch auf der Bühne thematisiert: Wenn Gurnemanz den jungen Parsifal in die Gralsburg führt und sich die Bühne zu verwandeln beginnt, erlebt der Zuschauer eine Aufhebung des gewöhnlichen Zeitempfindens. "Ich schreite kaum, doch wähn' ich mich schon weit", sagt Parsifal, und Gurnemanz antwortet: "Du siehst, mein Sohn, zum Raum wird hier die Zeit."

$$
-63-
$$

Der marschartige Glockenrhythmus, der das Schreiten der beiden anfänglich noch 
akzentuiert, wird in der folgenden Verwandlungsmusik allmählich in eine komplexe polyphone Satzstruktur überführt. Das langsame Tempo, die verschwebenden Rhythmen und die differenzierte Orchesterpolyphonie, von denen die Parsifal-Partitur durchzogen ist, sind dergestalt Ausdruck von Wagners Überzeugung, die Musik als tönende Philosophie habe den Zuhörer von der Welt der Erscheinung abzulenken und ihn zur Erkenntnis der ewigen Ideen hinzulenken, die außerhalb von Raum und Zeit stehen.

$$
-64-
$$

Am Schluß des Werkes werden Sprache und szenisches Bild in den flutenden Klangstrom der Musik zurückgenommen. Mit der vielfachen Wiederholung des Erlösungsworts, mit der Verschränkung und polyphonen Auffächerung der Stimmen und dem Durchwandern des Quintenzirkels, von As-Dur ausgehend und nach As-Dur zurückkehrend, entsteht ein harmonisches und melodisches Total, in dem die Gegensätze ineins zusammenfallen. Die erlösende Kraft der Musik saugt das Drama in sich auf. Sie wird zum Refugium einer Utopie, deren Realisierung sich allein im Kunstwerk vollzieht. [15]

Die nachfolgende Komponistengeneration ist in der Regel mit Schopenhauer bereits in frühen Jahren bekannt geworden. Hans Pfitzner beispielsweise hat etwa im Alter von zwanzig Jahren, also spätestens um 1890, Die Welt als Wille und Vorstellung gelesen. Er war Mitglied der Schopenhauer-Gesellschaft, besaß mehrere Werkausgaben und 
behauptete, jede Zeile daraus zu kennen. Sein Bekenntnis zu Schopenhauer, das 1938 veröffentlicht wurde, liest sich wie ein Gelöbnis: "Und dieses mein Bekenntnis", heißt es da, "soll zwei Eigenschaften haben: erstens soll es ein ewiges sein, denn ich werde nie von ihm abfallen [...]. Zweitens aber soll dieses Bekenntnis zu ihm ein vollkommenes und ganzes sein, $d$. h. ohne jede Einschränkung, also nicht etwa, daß ich diese oder jene Teile seines Gedankengebäudes geringer schätzte als andere, oder gar ablehnte [...]." $[16]$

$-66-$

Kein Wunder also, daß die Spuren der Schopenhauerschen Philosophie nicht nur in den Schriften Pfitzners allgegenwärtig sind, sondern auch in seinem Werk. Schon in seinem ersten Musikdrama Der arme Heinrich, dessen Textbuch ein Jugendfreund 1891 nach den Anweisungen des Komponisten geschrieben hat, wirft er einen pessimistischen Blick auf die Vergeblichkeit des menschlichen Strebens nach Glückseligkeit und feiert seine Überwindung durch liebendes Mitleid, durch die Bereitschaft zum Selbstopfer, zur Entsagung und zur religiösen Kontemplation.

$$
-67-
$$

Pfitzners dritte Oper Palestrina, deren Text er in den Jahren 1910/11 selbst verfaßt hat, liest sich über weite Strecken geradezu wie eine Schopenhauer-Paraphrase. Das vorangestellte Motto aus der Welt als Wille und Vorstellung gibt den Grundkonflikt des Werkes vor: Das "rein intellektuelle Leben der Menschheit", so das Zitat, "besteht in ihrer fortschreitenden Erkenntnis mittelst der Wissenschaften und in der Vervollkommnung der Künste, welche Beide, Menschenalter und Jahrhunderte hindurch, sich langsam fortsetzen, und zu denen ihren Beitrag liefernd, die einzelnen Geschlechter vorübereilen. Dieses intellektuelle Leben schwebt, wie eine ätherische Zugabe, [...] über dem weltlichen Treiben, dem eigentlich realen, vom Willen geführten Leben der Völker, und neben der Weltgeschichte geht schuldlos und nicht blutbefleckt die Geschichte der Philosophie, der Wissenschaft und der Künste." [17] 
Die Konfrontation des menschenscheuen Musikers Palestrina mit den Repräsentanten des Tridentiner Konzils bildet den äußeren Handlungsrahmen: Im Auftrag des Papstes soll Palestrina eine musterhafte Meßkomposition schreiben, um die in Verruf geratene Kirchenmusik zu retten. Palestrina aber läßt sich nicht zwingen. Zwar empfängt er in einer nächtlichen Vision die Inspiration zu einer Messe, aber er kommt nicht auf den Gedanken, sie politischen Interessen preiszugeben. Wehrlos läßt er sich von den päpstlichen Schergen einkerkern. Sein Sohn liefert die Noten aus, und schließlich feiert man Palestrina als den 'Retter der Musik'. Doch den Komponisten berührt dies kaum. Er hat seinen Frieden mit Gott gemacht und versenkt sich, an seiner Orgel sitzend, "leise spielend, in musikalische Gedanken, den Blick über die Tasten weg ins Weite gerichtet".

$$
-69-
$$

Gedankliches Zentrum des Werkes ist das Drama des einsamen Künstlers, der den Blick auf die Brutalität der Welt nicht ertragen kann und der sich "stumm verzweifelt" von der Außenwelt abkehrt, bis er - eigentlich gegen seinen Willen - die Inspiration zu seinem großen Werk empfängt. Palestrina, der im ersten Akt "verstört und zerstreut" vor seinen Notenblättern sitzt, ist das Gegenbild zu Hans Sachs, der am Johannismorgen in seiner Schusterstube historische Studien treibt und aus den Blättern seines Folianten immer nur den "alten Wahn" - Krieg, Gewalt und Sinnlosigkeit - herauslesen kann. Aber im Gegensatz zu Hans Sachs, der handelnd tätig wird und dem es gelingt, den "Wahn" zu "bemeistern", verfällt Palestrina der Resignation und der Weltflucht.

$$
-70-
$$

"Das Innerste der Welt ist Einsamkeit", sagt er und schließt ein Dante-Zitat an: "Wie schrecklich, / Sich plötzlich einsam tief im Wald zu finden / Wo in der Finsternis kein Ausweg ist." Zwar werden die Fremdheit und Einsamkeit des Genies in einer Welt, die an seinen Erzeugnissen keinen Anteil nimmt, auch von Schopenhauer mehrfach thematisiert. Aber Pfitzner geht hier noch über Schopenhauer hinaus, indem er seinen 
Protagonisten nicht nur an der Welt, sondern auch an seinem Künstlertum verzweifeln läßt: Gleichgültig findet sich Palestrina damit ab, daß der Papst seine Werke verbrennen will. Er glaubt nicht mehr an den Ewigkeitswert seiner Kunst: "Wie wäre Künstlers schaffendes Organ / Nicht auch dem Zeitlich-Trüben untertan?", fragt er resigniert. Er fühlt sich "in Sterblichkeit befangen", als "ein alter, todesmüder Mann / am Ende einer großen Zeit", dem alles, selbst das eigene Schaffen, sinnlos erscheint.

Auf dem Höhepunkt seiner Verzweiflung findet ein plötzliches Umschlagen der Erkenntnis statt: Ihm nähern sich in visionärer Schau "die verstorbenen Meister der Tonkunst vergangener Epochen, Palestrinas große Vorgänger". Sie fordern von ihm das letzte, große Werk, das er noch zu schaffen habe, den Schlußstein einer langen Kette, an der sie alle mitwirken mußten auf Geheiß des "alten Weltenmeisters, / der ohne Namen ist". Pfitzner hat hier Schopenhauers Vorstellung einer ideellen Kommunikation großer Geister visualisiert, die einander einsam durch Jahrhunderte hinweg die Hand reichen. Sie fügen Palestrina ein in eine imaginäre, Raum und Zeit umspannende Gemeinschaft. Aus ihnen spricht Palestrinas unbewußtes Wissen um seine keineswegs versiegte schöpferische Kreativität.

Diese Szene wie auch die folgende Inspiration zu der großen Messe ist eine bildliche Transformation dessen, was Wagner in seiner Beethoven-Festschrift (in Anlehnung an Schopenhauer) über den Zustand des komponierenden Genies ausgeführt hat. Die dort beschriebene Abwendung von der Außenwelt und die Versenkung in die Introspektion 
geht in Pfitzners Bühnenwerk in mehreren Stufen vor sich: Die Erscheinung der alten Meister ist ein Wachtraum. Raum und Zeit werden zwar transzendiert, aber sie bleiben noch kenntlich: Die Tonkünstler der Vergangenheit sind in die Tracht ihrer jeweiligen Zeit und ihres Landes gekleidet, und was sie sagen, entspringt der seelischen Innenwelt des Künstlers, der mit den Tiefenschichten seines Bewußtseins in einen imaginären Dialog eintritt.

Dieser Versenkung in die Introspektion folgt ein kurzes Erwachen, ein Wiederaufflammen der Verzweiflung, die sich alsbald in ein zweites Traumbild auflöst. Palestrina sitzt, wie es in der Regieanweisung heißt, "aufrecht, nicht angelehnt, mit geschlossenen Augen; es ist vollständig dunkel". Sein letzter Aufschrei: "Allein in dunkler Tiefe / Voll Angst ich armer Mensch / rufe laut nach oben", beschwört die Klage des De profundis. Zugleich erinnert dies an eine Stelle in Wagners Beethoven-Schrift, in der vom plötzlichen, schreckhaften Erwachen aus der Traumwelt des Unbewußten die Rede ist: "Aus den beängstigendsten solcher Träume erwachen wir mit einem Schrei", heißt es dort, "in welchem sich ganz unmittelbar der geängstigte Wille ausdrückt." [18]

Der Schrei - die unmittelbare Expression des Leidens an die "Schallwelt" - ist für Wagner "in allen Abschwächungen seiner Heftigkeit bis zur zarteren Klage des Verlangens [...] das Grundelement jeder menschlichen Kundgebung an das Gehör". Der Schrei ist nach seiner Überzeugung aber auch die anthropologische Grundlage der Musik. Aus ihm entwickelt sich die Tonkunst als äußere Entsprechung zur inneren 
Schau des Träumenden. [19]

Dementsprechend entbindet Palestrinas Klageruf die musikalische Inspiration. Jetzt werden die Erscheinungsformen Raum und Zeit endgültig abgestreift. Hinter ihnen scheinen die ewigen Ideen hervor, die sich in musikalischen Gestalten aussprechen. Pfitzner übersetzt die Klangvision sinnfällig in die Bildersprache der Renaissance, indem er einen kleinen Engel - "von hellem Schein beleuchtet" - auf der Rücklehne des Stuhles, auf dem Palestrina sitzt, die Melodie des Kyrie anstimmen läßt. Palestrina "ergreift mechanisch die Feder" und singt die Melodie nach.

$-76-$

Seine Verzweiflung ist überwunden, er durchlebt jene Ekstase, von der Wagner in seiner Beethoven-Schrift berichtet hat. "Wie durch die eigne Brust / Selig nun zieht / Allmächt'ge Schöpferlust", jubelt Palestrina. Bei Wagner heißt es (wie oben bereits zitiert), daß "diese ungeheure Überfluthung aller Schranken der Erscheinung [...] im begeisterten Musiker nothwendig eine Entzückung hervorruf $[\mathrm{t}]$, mit welcher keine andere sich vergleichen ließe: in ihr erkennt sich der Wille als allmächtiger Wille überhaupt." [20]

Schopenhauers Gedanke der Überwindung von Zeit und Raum, der in der Inspirationsszene Gestalt gewinnt, bestimmt auch die musikalische Struktur des Werkes - allerdings auf andere Weise, als wir es in Wagners Parsifal beobachten konnten. Indem Pfitzner sein Künstlerdrama in einer konkreten historischen Situation spielen läßt - Rom 1563 -, steht ihm eine Fülle innermusikalischer Verweise zur Verfügung, die in die Zeit der Renaissance, ja sogar in die Zeit vor dem historischen Palestrina zurückführen.

$$
-78-
$$

Das Vorspiel beginnt mit einer Intonation leerer Quinten und Quarten in polyphoner Verschränkung: 
Notenbeispiel 5: Hans Pfitzner, Palestrina, Vorspiel I; T. 1ff:
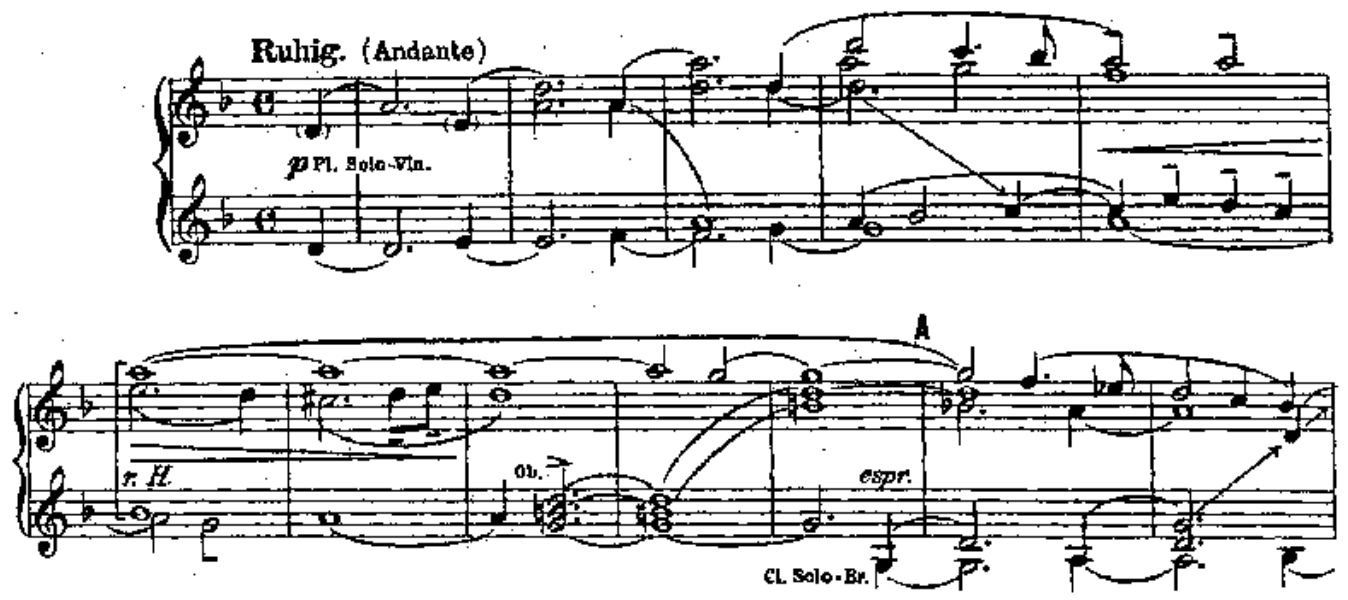

Damit erzeugt Pfitzner den Eindruck des Archaischen, Altertümlichen. Die Assoziation mittelalterlicher Musik stellt sich ein. Die Imitationsstruktur erinnert wiederum an Stilmittel der klassischen Vokalpolyphonie. Schon nach wenigen Takten entstehen jedoch Quartenakkorde und Sekundreibungen, die eindeutig der Tonsprache des frühen 20. Jahrhunderts angehören. Die Instrumentation dieser Quint-Quart-Imitationen mit Flöte und Solovioline reduziert den Reichtum des nachwagnerschen Orchesters auf ein sparsames, lineares Gerüst.

Auf diese Weise entsteht eine herb und streng anmutende Klanglichkeit, in der sich Altertümliches und Modernes eigenwillig verbinden. Mit dem Ineins aus Alt und Neu 
will Pfitzner dem Hörer die "Idealität der Zeit" - nach seiner Überzeugung eine Kernaussage des Werkes - nahebringen. [21] Die musikgeschichtliche Strecke, die Pfitzner im Palestrina durchmißt, reicht von dem mittelalterlichen Kolorit des anfänglichen Quint-Quart-Motivs über Stilelemente der Palestrina-Zeit bis hin zum Idiom der Moderne, der Pfitzner angehört.

$$
-80-
$$

So stellt er den leidenden Palestrina in der musikalischen Sprache des frühen 20. Jahrhunderts als einen innerlich zerrissenen, modernen Menschen dar - besonders deutlich wird dies in dem Monolog, der die Erscheinung der alten Meister vorbereitet, und in Palestrinas Antworten auf ihre Reden. Die Meister der Vergangenheit singen jeweils in der musikalischen Sprache ihrer Zeit, sie verwenden alte Klauseln in modaler Harmonik und singen in Organalklängen mit Quint- und Oktavparallelen.

Die Messe selbst verwendet nur vereinzelt Zitate aus der berühmten Missa Papae Marcelli des historischen Palestrina. Auf eine historisch getreue Stilkopie kam es Pfitzner demnach nicht an. Vielmehr verschmilzt er die einander fremdartigen musikalischen Elemente aus unterschiedlichen Zeitebenen $\mathrm{zu}$ einer individuellen Tonsprache, so daß sie zwar kenntlich bleiben, zugleich aber eine ideelle Einheit bilden. Die Verbindung von Stilelementen der frühen mit solchen der späten Zeit ist so sinnfällig, daß sie wie die Steine an jener Kette erscheinen, von denen die alten Meister dem zweifelnden Palestrina berichten.

Das musikalisch wohl eindringlichste Thema der Partitur symbolisiert Palestrinas künstlerische Vollendung: 


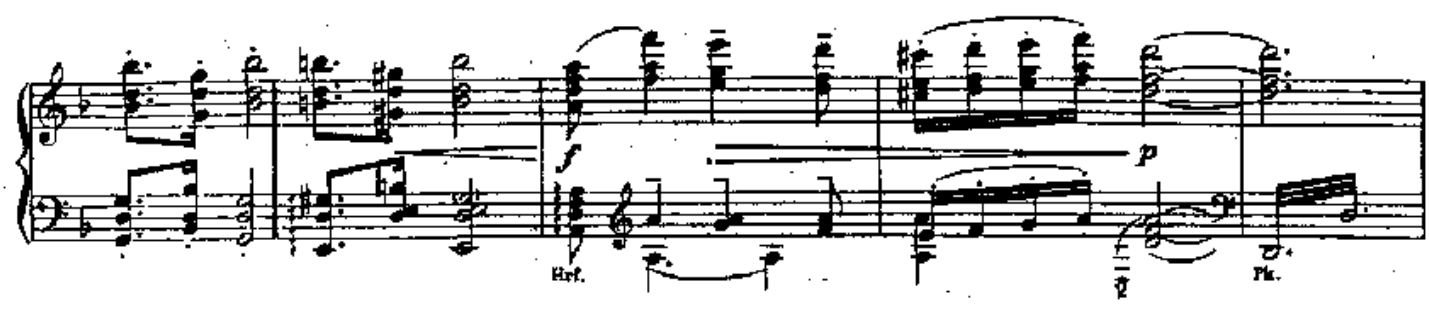

Ein signalartiges, punktiertes Motiv in g-Moll wird im folgenden Takt auf einem Septklang über E wiederholt und mündet nach einem emphatischen Aufschwung in einen Kadenzvorgang mit einer bekräftigenden Sechzehntelfiguration. Die ebenfalls archaisch anmutende Aura dieses Motivs ergibt sich vor allem aus dieser Kadenzfloskel mit ihrem 'schließenden' Charakter. Palestrina ist der "letzte Stein" in einer langen Kette, die sich mit seinem Werk schließt. So verstand Pfitzner wohl auch seine eigene musikgeschichtliche Stellung, die er auf die Zeit des historischen Palestrina zurückprojiziert: Im Augenblick einer Zeitenwende, die zu Atonalität und Zwölftontechnik führt, begriff er sich als Vollender der musikgeschichtlichen Epoche der Romantik. Deshalb liegt - in zweifacher Perspektive - Endzeitstimmung über dem Drama.

Pfitzner hat den dritten Akt des Palestrina als Gegenentwurf zum Schlußtableau der Meistersinger aufgefaßt. Thomas Mann berichtet, wie Pfitzner in einem Gespräch auf den Unterschied zwischen beiden Werken hingewiesen hat: "Am Ende der 'Meistersinger' eine lichtstrahlende Bühne, Volksjubel, Verlöbnis, Glanz und Gloria; bei mir 
der freilich auch gefeierte Palestrina allein im Halbdunkel seines Zimmers unter dem Bild der Verstorbenen an seiner Orgel träumend. Die 'Meistersinger' sind Apotheose des Neuen, ein Preis der Zukunft und des Lebens; im 'Palestrina' neigt alles zum Vergangenen, es herrscht darin Sympathie mit dem Tode." [22]

Thomas Mann hat diese "Sympathie mit dem Tode" - der Begriff stammt bekanntlich von ihm selbst, nämlich aus seinem Roman Der Zauberberg - als Kennzeichen einer Rückwendung zur Romantik gedeutet. Palestrina sei das "Produkt einer melancholisch abgewandten, ja zeitwidrigen Geistigkeit", "etwas Letztes und mit Bewußtsein Letztes aus der schopenhauerisch-wagnerischen, der romantischen Sphäre", und Thomas Mann sah in diesem Werk "mit seinen dürerisch-faustischen Wesenszügen, seiner metaphysischen Stimmung, seinem Ethos von 'Kreuz, Tod und Gruft'", den "wehmutsvollen Ausklang einer national-künstlerischen Bewegung, die mit Hans Pfitzner, seiner eigenen Einsicht nach, sich ruhmvoll endigt." [23]

Thomas Mann schrieb diese Sätze im Jahre 1917, kurz nach der Uraufführung des Palestrina, während des Ersten Weltkriegs also, der einen epochalen Umbruch markiert. Was Thomas Mann damals noch nicht sehen konnte, ist für uns heute evident: Pfitzners Endzeitbewußtsein, seine dezidierte Rückwendung zur Romantik - selbst wenn sie im Zeichen der strengen Geistigkeit Arthur Schopenhauers steht - birgt Gefahren in sich. Bekannt ist seine Anfälligkeit für eine Zeitstimmung, die wenig später fatale politische Konsequenzen zeitigen sollte. Pfitzners romantisch getönter Nationalismus, seine politisch reaktionären Anwandlungen, die ihn schließlich die Sympathie Thomas Manns gekostet haben, gehen einher mit einer Kunstauffassung, die für die Musik eines Busoni oder Schönberg - gelinde gesagt - keinerlei Verständnis aufzubringen vermochte.

$$
-86 \text { - }
$$

Wer Pfitzner deshalb gegen die musikalische Avantgarde ausspielen wollte, würde jedoch den hohen Wert seiner künstlerischen Individualität verkennen. Pfitzner bleibt nicht zuletzt dank Arthur Schopenhauer - den Idealen des 19. Jahrhunderts vom 
'Wahren, Schönen, Guten' verpflichtet. Der Ewigkeitswert der Kunst steht für Pfitzner weit über der Bedeutung des politischen Tagesgeschäfts - diese Haltung hat man ihm denn auch als typisch 'deutsche' Weltfremdheit vorgeworfen. Er ist durchdrungen von einem unerschütterlichen Glauben an die innere Notwendigkeit des künstlerischen Schaffens, das eine metaphysische Dignität besitzt. Der Künstler ist das Werkzeug einer höheren Macht.

Er ist kreativ nach einem Gesetz, das er selbst nicht kennt, und steht im Dienst jener Vervollkommnung des geistigen Lebens der Menschheit, von dem das Schopenhauer-Motto spricht, das Pfitzner seinem Musikdrama Palestrina vorangestellt hat.

Daher weicht Palestrinas anfängliche Verzweiflung dem Gefühl einer "ruhigen, fast heiteren Ergebung", sobald er sein "Erdenpensum", die Komposition der Messe, vollendet hat. Sein Blick bleibt an den bunten Bildern der Erscheinung nicht mehr haften, er ist stets in die Weite gerichtet. Damit hat Palestrina jene dauerhafte Gemütsruhe erreicht, die Schopenhauer allein dem Weltüberwinder zugesteht.

Folgerichtig trägt das Musikdrama den Untertitel "Musikalische Legende". Palestrina ist Heiliger in einem doppelten Sinne: als "Retter der Musik" und mehr noch als Märtyrer seiner Kunst. Im Augenblick seines großen äußerlichen Triumphes sieht er sich selbst als ein zerschlagenes Gefäß, aus dessen Scherben der Liebeshauch der Musik aufsteigt. Der geistige Heroismus des Künstlers, der sich gegen die Forderungen der Außenwelt zur Wehr setzt, auch wenn er an ihnen zugrunde geht, verdankt sich Schopenhauer. 


\section{$* * *$ \\ $-89-$}

Bruno Walter berichtet, daß Gustav Mahler - zumindest in seiner Hamburger Zeit, also in den 90er Jahren des 19. Jahrhunderts - "ganz unter Schopenhauers Einfluß" gestanden habe. [24] Allerdings war Mahler Eklektizist. In seinem Weltbild verbinden sich Gedanken Schopenhauers und Richard Wagners mit Naturmystik, Okkultismus, Kabbalismus, lebensphilosophischen Aspekten und christlicher Unsterblichkeitslehre zu einer eigenwilligen Synthese. [25] Insofern war Gustav Mahler ein typischer Repräsentant jener Zeitstimmung des Fin de siècle, in der geschlossene philosophische Systeme zunehmend obsolet wurden.

$$
-90-
$$

Gleichwohl ist der Einfluß Schopenhauers auf sein Denken allenthalben greifbar. Wie Schopenhauer, Wagner und Pfitzner war auch Gustav Mahler vom Leidenscharakter des Daseins überzeugt. Den Zwängen der zivilisierten Welt, dem 'Weltgetümmel', das ihm

nur Ekel und Überdruß verschafft, stellt er die Schönheit der Natur und der Kunst als das 'ganz Andere' entgegen.

$$
-91-
$$

Mahlers Denken ist dualistisch. Er fühlt sich gespalten in eine scheinhafte Existenz, die ihm durch das verhaßte Tagesgeschäft aufgezwungen wurde - konkret: durch seine Arbeit als Dirigent und Operndirektor mit ihrem bürokratischen Ballast, ihrem Zeitaufwand und der Verstrickung in 'allzumenschliche' Intrigen und Machtspiele -, und in seine eigentliche Existenz als kreativer Künstler. Mahler gestaltet in seiner Musik 
diese Grunderfahrung mit schonungsloser Radikalität. Schopenhauers Philosophie liefert ihm dafür das gedankliche Fundament.

$$
-92-
$$

Mahler hat gegenüber Freunden verschiedentlich gesagt, daß außer Wagner (in seiner Beethoven-Schrift) nur noch Arthur Schopenhauer in der Welt als Wille und Vorstellung über das Wesen der Musik Wertvolles zu sagen gehabt hätte. [26] Sein zentrales Bekenntnis: "Symphonie heißt mir eben: mit allen Mitteln der vorhandenen Technik eine Welt aufbauen" [27], bezieht sich direkt auf Schopenhauers Diktum, die Musik sei eine ebenso unmittelbare Objektivation des Willens wie die Welt selbst. Zugleich kommen hier auch antike Vorstellungen von der Musica mundana als Spiegel der kosmischen Ordnung zum Tragen: "Man ist sozusagen selbst nur ein Instrument, auf dem das Universum spielt", heißt es in einem Brief. [28]

$$
-93-
$$

Wenn die Musik ein Abbild der Welt ist, so muß das Glück, das sie gewährt, ebenfalls ein Teil dieser Welt sein. Denn über Wesen und Wirkung der Musik liest man bei Schopenhauer: "Das unaussprechlich Innige aller Musik, vermöge dessen sie als ein so ganz vertrautes und doch ewig fernes Paradies an uns vorüberzieht, so ganz verständlich und doch so unerklärlich ist, beruht darauf, daß sie alle Regungen unsers innersten Wesens wiedergibt, aber ganz ohne die Wirklichkeit und fern von ihrer Quaal." [29]

$$
-94-
$$

Gustav Mahlers Musik macht sich auf die Suche nach diesem 'fernen Paradies', und sie tritt die Reise inmitten der miserablen Wirklichkeit an, die sie transzendieren will. Daher werden die beiden einander entgegengesetzten Aspekte der Welt in seinen Symphonien 
oftmals hart miteinander konfrontiert, und daher erscheint Mahlers Musik dort, wo sie rückhaltlos 'schön' ist, immer auch gefährdet.

$$
-95-
$$

Ironie und Groteske sind Ausdruck einer Trauer, die sich humoristisch maskiert, und die schockhaften Einbrüche des Schrecklichen in das Schöne offenbaren die Ambivalenz von Mahlers Weltsicht. Ganz selten darf sich das Schöne ungehemmt aussingen - so im Adagietto der Fünften Symphonie und im vierten der Lieder nach Texten von Friedrich Rückert, das im Spätsommer des Jahres 1901 komponiert wurde.

$$
-96-
$$

Rückerts Text "Ich bin der Welt abhanden gekommen" hat Mahler als Beschreibung des Zustands der ästhetischen Kontemplation im Sinne Schopenhauers aufgefaßt. 'Welt' meint in Mahlers Verständnis jenes von Hetze, Lüge und Heuchelei bestimmte mechanische Getriebe des Alltagslebens, in dem man seine Zeit nur 'verderben' kann, wie es bei Rückert heißt. 'Der Welt abhanden' kommen bedeutet demgegenüber, sich aus dem 'Weltgetümmel' zurückzuziehen und die eigene Seele im Anschauen der ewigen Ideen zu beruhigen.

-97 -

Wie bei Schopenhauer, Wagner und Pfitzner erschließt sich das 'ferne Paradies' dem Künstler durch die Introspektion. Daher sind Einsamkeit und Weltflucht für Mahler Bedingungen der Erfahrung des ganz Anderen, des transzendenten Reichs der Schönheit. Dieser Rückzug wird von dem Dichter des Liedes in die Metapher des 'Sterbens' gefaßt: "Ich bin gestorben dem Weltgetümmel / und ruh' in einem stillen Gebiet."

$$
-98-
$$

Dieses 'stille Gebiet' ist in Mahlers Interpretation das Reich der Kunst, in der das "ferne Paradies" erfahren werden kann. In den beiden letzten Versen: "Ich leb' allein in meinem Himmel, / in meinem Lieben, in meinem Lied", sind die Kunst als Refugium des Schönen und die Liebe als eine überirdische, allen Wesen zugewandte erlösende Kraft zu einer untrennbaren Einheit verbunden. Gerade in der Entrückung kann das Subjekt 
nach Schopenhauer zum innersten Wesen der Welt vordringen, und im Augenblick der ästhetischen Kontemplation sind die Reibungen und schmerzvollen Gegensätze für einen Augenblick überwunden.

$$
\text { - } 99 \text { - }
$$

Mahler faßt diesen Zustand in eine Musik von sphärenhafter Entrücktheit. Das elftaktige Vorspiel umschreibt zunächst den allmählichen Aufstieg der Seele in den 'Himmel', von dem in Rückerts Text die Rede ist:

Notenbeispiel 7: Gustav Mahler, Ich bin der Welt abhanden gekommen: 


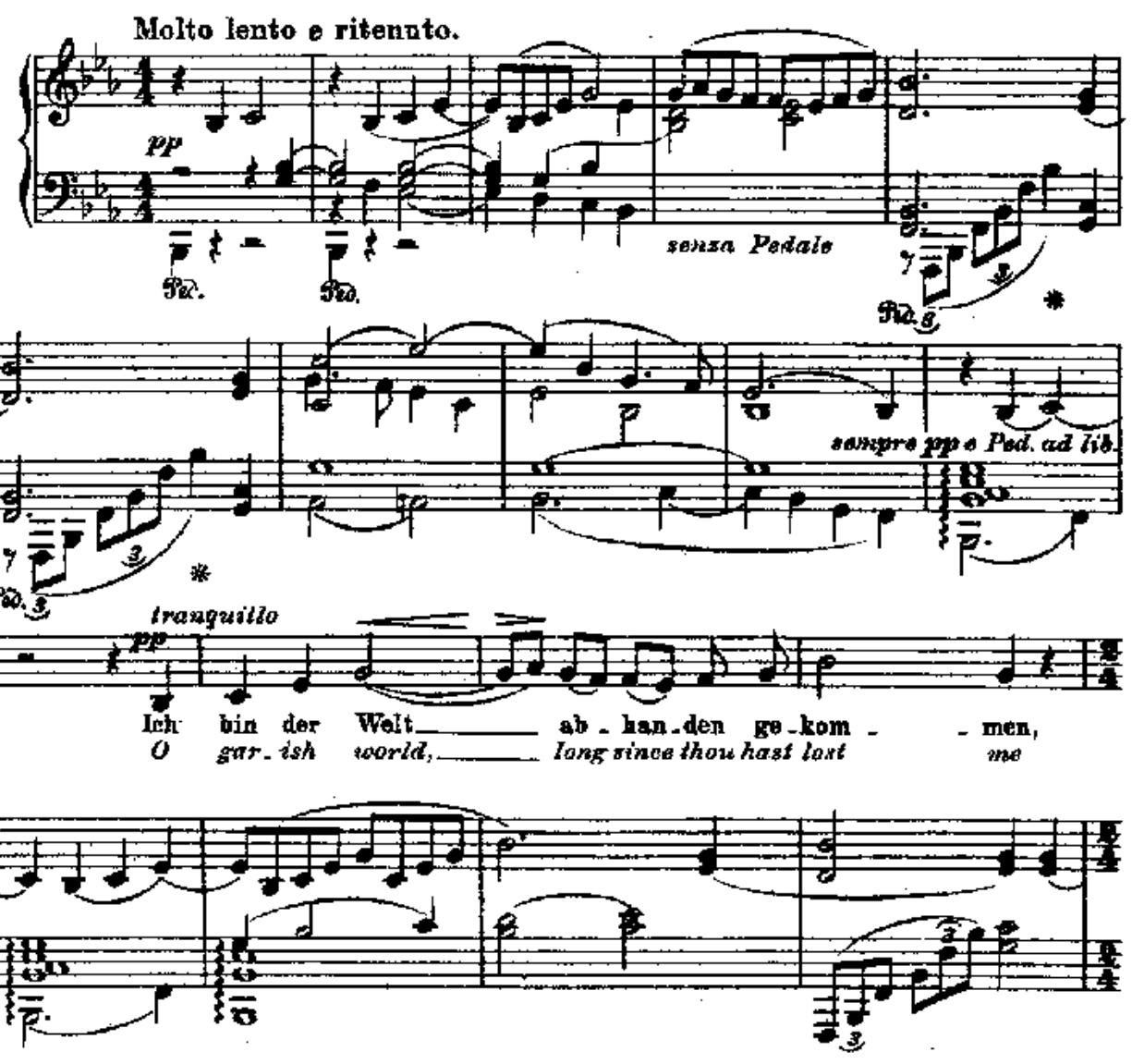

Es beginnt mit einem aufsteigenden Ganzton über einem tiefen $b$. Dieser Anstieg weitet sich im folgenden Takt sukzessiv zur Quarte, sodann zur Sexte (immer vom Ausgangston $b$ gedacht). Schon diese Öffnung des Klangraums, der durch die simultane Gegenbewegung nach unten (Takt 3) noch verstärkt wird, beschreibt einen Prozeß der Bewußtseinserweiterung. Die Melodie der Singstimme wiederholt diesen Aufstieg und verliert sich sodann in arabeskenhafte Linien, die jede Zielstrebigkeit, jede Dramatik verleugnen und sich in immer erneuten Wellen auf- und abwärts bewegen.

Singstimme und Begleitung treten alsbald in einen subtilen Dialog miteinander, indem die Instrumentalstimme oftmals die Melodie des Sängers antizipiert oder dessen Pausen mit eigenständigem Kommentar füllt. Die Aussprache des lyrischen Ich und die Klangrede des Instruments erscheinen nicht als Gegensätze, sondern vielmehr als zwei innig verbundene Erscheinungsformen ein und derselben psychischen Erfahrung. Diese 
Musik atmet, sie ist durchsetzt von Pausen, in denen sich die "Kunst des tönenden Schwei-

gens", wie Wagner die instrumentalen Passagen seiner Musikdramen einmal genannt hat [30], entfalten kann.

Nur an einer Stelle wächst der Instrumentalpart an Ausdrucksintensität über die Singstimme hinaus: Es ist die zentrale Stelle: "und ruh' in einem stillen Gebiet". In den beiden Takten, die darauf folgen, schweigt die Singstimme; das Klavier beziehungsweise das Orchester schwingt sich in die hohe Lage auf und verdichtet sich zu einer Melodie, die in sensitiven Terzen geführt ist - Zeichen für die Vorahnung von der Vergänglichkeit einer Schönheit, die so vollkommen ist, daß der Mensch sie kaum noch ertragen kann.

Nach diesem expressiven Höhepunkt sinkt die Musik allmählich in die tiefe Lage zurück. Die Singstimme beschreibt nur noch absteigende Intervalle, und sie schließt mit einem Ganzton abwärts - Spiegel und Rücknahme des aufsteigenden Ganztons, mit dem das Lied begonnen hat. Auch der Instrumentalpart schwingt allmählich aus und kommt in einem Es-Dur-Dreiklang zum Stillstand.

\section{- $103-$}

Das Lied endet, bevor der Einbruch der Außenwelt den Zustand der paradiesischen Selbstversunkenheit zerstören kann, wie dies beispielsweise im Adagietto der Fünften Symphonie geschieht. Aber der sensible Hörer weiß um die Gefährdung des Schönen durch das Schreckliche. Gerade deshalb ist dieses Lied so kostbar. In ihm ist die temporäre Erlösung, die Schopenhauer dem Menschen in der ästhetischen 
Kontemplation zugesteht, zur Vision eines ewigen Augenblicks erhoben.

SEITE: 101

\section{Anmerkungen}

${ }^{1}$ Dieser Text basiert auf einem Vortrag, der im Rahmen des Symposions Arthur Schopenhauer und die Künste am 18. Oktober 1998 in Frankfurt/Main gehalten wurde.

[Zurück zum Text]

2 Dazu ausführlich: Ulrike Kienzle, Das Weltüberwindungswerk. Wagners 'Parsifal' - ein szenischmusikalisches Gleichnis der Philosophie Arthur Schopenhauers, Laaber 1992.

\section{[Zurück zum Text]}

${ }^{3}$ Briefwechsel zwischen Wagner und Liszt, Band 2, Leipzig 1887, S. 45.

\section{[Zurück zum Text]}

${ }^{4}$ Arthur Schopenhauer, Die Welt als Wille und Vorstellung, Band II, Zürich 1977, S. 627 und 656. (Bei Schopenhauer-Verweisen werden stets die Bände der Zürcher Ausgabe zugrundegelegt.)

\section{[Zurück zum Text]}

${ }^{5}$ Richard Wagner, Brief an August Röckel vom 23. August 1856, zitiert nach: ders.: Briefe, hg. von Hanjo Kesting, München/Zürich 1983, S. 336.

\section{[Zurück zum Text]}

6 Thomas Mann, Leiden und Größe Richard Wagners, in: ders.: Wagner und unsere Zeit. Aufsätze, Betrachtungen, Briefe, hg. von Erika Mann, Frankfurt/M. 1983, S. 95 und 98.

[Zurück zum Text]

${ }^{7}$ Arthur Schopenhauer, Parerga und Paralipomena II, S. 326.

[Zurück zum Text]

${ }^{8}$ Richard Wagner an Mathilde Wesendonck. Tagebuchblätter und Briefe 1853-1871, Berlin 1904, S. 217. 


\section{[Zurück zum Text]}

${ }^{9}$ Friedrich Nietzsche, Die Geburt der Tragödie aus dem Geiste der Musik, in: ders.: Werke in sechs Bänden, hg. von Karl Schlechta, München/Wien 1980, Band 1, S. 116.

[Zurück zum Text]

${ }^{10}$ Arthur Schopenhauer, Die Welt als Wille und Vorstellung I, S. 327.

[Zurück zum Text]

${ }^{11}$ Arthur Schopenhauer, Die Welt als Wille und Vorstellung I, S. 332 und 322.

[Zurück zum Text]

12 Richard Wagner, Über die Benennung 'Musikdrama', in: ders.: Sämtliche Schriften und Dichtungen, Band 9, S. 306.

\section{[Zurück zum Text]}

${ }^{13}$ Richard Wagner, Beethoven, in: ders.: Sämtliche Schriften und Dichtungen, Band 9, S. 72 f.

\section{[Zurück zum Text]}

14 Vergleiche dazu auch: Ulrike Kienzle, Nürnberg als Wille und Vorstellung. Auf den Spuren der Philosophie Schopenhauers in Wagners 'Meistersinger'-Dichtung, in: Programmbuch der Bayreuther Festspiele 1997, S. 106-139.

\section{[Zurück zum Text]}

${ }^{15}$ Vergleiche dazu ausführlicher: Ulrike Kienzle, Das Weltüberwindungswerk, 1992.

[Zurück zum Text]

${ }^{16}$ Hans Pfitzner, Mein Bekenntnis zu Schopenhauer (1938), in: ders.: Sämtliche Schriften, Band 4, hg. von Bernhard Adamy, Tutzing 1987, S.483.

[Zurück zum Text]

${ }^{17}$ Hans Pfitzner, Palestrina, Klavierauszug von Felix Wolfes, Berlin 1916.

[Zurück zum Text]

18 Richard Wagner, Beethoven, S. 69.

[Zurück zum Text]

${ }^{19}$ Richard Wagner, Beethoven, S. 69 f.

[Zurück zum Text]

${ }^{20}$ Richard Wagner, Beethoven, S. 73.

[Zurück zum Text]

${ }^{21}$ Hans Pfitzner, Mein Hauptwerk, zitiert nach: Stefan Kunze, Zeitschichten in Pfitzners 'Palestrina', in: Symposium Hans Pfitzner, Berlin 1981, Tagungsbericht, hg. von Wolfgang Osthoff, Tutzing 1984, S. 69.

\section{[Zurück zum Text]}


${ }^{22}$ Thomas Mann, Betrachtungen eines Unpolitischen, Frankfurt a.M. 1988, S. 415.

[Zurück zum Text]

23 Thomas Mann, Betrachtungen eines Unpolitischen, S. 399 f.

[Zurück zum Text]

${ }^{24}$ Bruno Walter, Gustav Mahler. Ein Porträt, 2. Auflage, Berlin und Frankfurt/M. 1957, S. 102.

[Zurück zum Text]

${ }^{25}$ Siehe dazu Constantin Floros, Gustav Mahler, Band 1: Die geistige Welt in systematischer Darstellung, Wiesbaden 1977.

\section{[Zurück zum Text]}

26 Nach Gustav Mahler, Briefe. Neuausgabe, erweitert und revidiert von Herta Blaukopf, Wien und Hamburg 1982, S. 101.

[Zurück zum Text]

${ }^{27} \mathrm{Zu}$ Natalie Bauer-Lechner, Sommer 1895, zitiert nach: Herbert Killian (Hg.), Gustav Mahler in den Erinnerungen von Natalie Bauer-Lechner, Hamburg 1984, S. 35.

[Zurück zum Text]

${ }^{28}$ Gustav Mahler, Briefe 1879-1911, hg. von Alma Maria Mahler, Berlin, Wien und Leipzig 1924, S. 163.

[Zurück zum Text]

${ }^{29}$ Arthur Schopenhauer, Die Welt als Wille und Vorstellung I, S. 331.

[Zurück zum Text]

${ }^{30}$ Richard Wagner an Mathilde Wesendonck, Tagebuchblätter und Briefe 1853-1871, S. 68.

[Zurück zum Text]

Dokument erstellt am 15. Juni 1999

PD Dr. Wolfgang Krebs, Clemens Gresser 